\title{
Development and Validation of High Performance Liquid Chromatographic Analysis of Residual N,N-Dimethylformamide in Spent Medium after Biodegradation by Paracoccus denitrificans SD1
}

\author{
Sanjeevkumar Sanganal, Guruprasad B. Kulkarni, and Timmanagouda B. Karegoudar \\ Department of Biochemistry, Gulbarga University, Gulbarga, Karnataka 585106, India \\ Correspondence should be addressed to Timmanagouda B. Karegoudar; goudartbk@gmail.com
}

Received 30 March 2013; Accepted 22 April 2013

Academic Editors: V. L. Cebolla, L. Chen, and M. C. Monti

Copyright (C) 2013 Sanjeevkumar Sanganal et al. This is an open access article distributed under the Creative Commons Attribution License, which permits unrestricted use, distribution, and reproduction in any medium, provided the original work is properly cited.

\begin{abstract}
N,N-Dimethylformamide (DMF) is a toxic organic solvent commonly found in the textile and pharmaceutical industrial effluents. The DMF degradation was successfully archived by bacterial strain Paracoccus denitrificans SD1. The study demonstrates the high performance liquid chromatographic (HPLC) approach for the estimation of residual DMF in liquid medium. The investigation mainly focuses on the method development for the detection and quantification of DMF. The bacterium is capable of utilizing DMF $(1 \% \mathrm{v} / \mathrm{v})$ as the sole source of carbon and nitrogen. Utilization of DMF by the bacterium was investigated at regular intervals of time to check the complete degradation at a particular period. The method was validated based on the precision, accuracy, limit of detection, and limit of quantification. Herein, the method was executed in liquid chromatographic condition which enables direct analysis of aqueous samples from the spent medium avoiding the extraction and prederivatization. This improved method allows estimation of residual DMF from the aqueous medium in adequate ranges of precision and accuracy with $99.17 \%$ and $99.43 \%$ recovery, respectively. The method was validated by investigating the limit of detection (LOD) and limit of quantification (LOQ) of 0.2 and $0.40 \mathrm{mg} / \mathrm{l}$, respectively. The method was found to be precise for detection of DMF by using liquid chromatography.
\end{abstract}

\section{Introduction}

N,N- Dimethylformamide (DMF) is a widely used aliphatic organic solvent in chemical, pharmaceutical, and textile industries. Since it is used for recovery of organic compounds, hence considerable amounts of DMF are found in textile and pharmaceutical industrial effluents causing adverse effects on environment and human health $[1-4]$. Because of its high dielectric constant, it has wide applications in the production of polyurethane, rubber, dyes, wood, leather, films, paper, and pesticides [5]. Globally the demand of DMF is consistently increasing in parallel with industrial activities, resulting in the higher accumulation of DMF in the environment through industrial effluents. It is readily absorbed through oral, dermal, and inhalation exposure [6, 7]. The extents of toxicity induced by DMF are hepatotoxicity, embryotoxicity, teratogenicity, and possible carcinogenicity. Long-term exposure to DMF might also cause irreversible alterations in mitochondrial DNA [5].

The treatment of DMF has gained a considerable attention; it can be recycled by distillation to mother liquors or disposed by incineration $[3,8]$. The chemical methods show slower rate of degradation; bioremediation might represent a viable alternative for the DMF removal from industrial effluents. The previous reports have successfully demonstrated the use of specialized bacterial free cells capable of utilizing DMF as the sole source of carbon and nitrogen [9-12]. We have recently reported the removal of DMF from industrial effluent by using immobilized Ochrobactrum sp. DGVK1 in PVA-alginate blended matrix. The investigation provides the clear idea on the treatment of DMF by both batch and continuous degradation modes [13]. 
To understand the degradation efficiency or rate, estimation of residual DMF was needed at regular intervals during bacterial degradation in the fermentation medium. DMF can be estimated by using high performance liquid chromatography $[12,13]$, whereas the methylated amines are estimated by using gas chromatography, but it requires prederivatization process before analysis. In the present study we have developed the optimized conditions for estimation and quantification of DMF by HPLC. The dimethylamine (DMA) and ammonia were estimated by spectrophotometric method at regular intervals of time. The investigation mainly focused on the validation of different parameters for the estimation of residual concentration of DMF from the bacterial fermentation medium.

\section{Materials and Methods}

2.1. Chemicals. Dimethylformamide was procured from Sigma-Aldrich, USA. HPLC grade water was obtained from Millipore, Millipore Corporation, Billerica, MA, USA. HPLC grade acetonitrile was procured from Merck chemicals, India. Sodium dihydrogen phosphate and culture media ingredients were purchased from Himedia, Mumbai, India. Filters $0.45 \mu \mathrm{m}$ and $0.2 \mu \mathrm{m}$ Nylon 6, 6 membranes were procured from Pall Corporation, USA. All other chemicals used in this study were of analytical grade.

2.2. Bacterial Strain and Growth Conditions. The strain Paracoccus denitrificans SD1 was previously isolated from coal mine leftovers in our laboratory. It was previously identified as Ochrobactrum sp. DGVK1 on $16 \mathrm{~S}$ rRNA gene typing. However, the whole genome sequence provided a clear basis for its correct identity as Paracoccus denitrificans SD1 [14]. This strain is capable of utilizing DMF as a sole source of carbon and nitrogen source. The bacterium was grown aerobically in mineral salt medium having the following composition: $\mathrm{K}_{2} \mathrm{HPO}_{4}$ 6.3; $\mathrm{KH}_{2} \mathrm{PO}_{4}$ 1.8; $\mathrm{MgSO}_{4} \cdot 7 \mathrm{H}_{2} \mathrm{O} 0.1 ; \mathrm{MnSO}_{4} \cdot 4 \mathrm{H}_{2} \mathrm{O}$ $0.1 ; \mathrm{CaCl}_{2} \cdot 2 \mathrm{H}_{2} \mathrm{O} 0.1 ; \mathrm{FeSO}_{4} \cdot 7 \mathrm{H}_{2} \mathrm{O} 0.1 ; \mathrm{NaMoO}_{7} \cdot 7 \mathrm{H}_{2} \mathrm{O} 0.006$. The $\mathrm{pH}$ of the medium was adjusted to 7.0. Filter-sterilized DMF $(1.0 \%, v / v)$ was supplied as the sole source of carbon and nitrogen.

\subsection{Degradation of DMF by Paracoccus denitrificans SD1.} The free cells of Paracoccus denitrificans SD1 were inoculated ( $2 \mathrm{~mL}$ of exponential cells; $5.5 \times 10^{9} \mathrm{CFU} \mathrm{mL}^{-1}$ ) in $250 \mathrm{~mL}$ Erlenmeyer flask containing $50 \mathrm{~mL}$ of MM1 medium with $(1.0 \%, \mathrm{v} / \mathrm{v}) \mathrm{DMF}$. The cultures were then incubated at $30^{\circ} \mathrm{C}$ and a portion of spent medium was withdrawn at every $12 \mathrm{~h}$ time interval for estimation of residual DMF. Control experiments were carried out with uninoculated flasks containing MM1 medium supplied with 1\% (v/v) DMF.

2.4. Sample Preparation. The samples were withdrawn at every $12 \mathrm{~h}$ intervals to estimate the residual DMF in the spent medium. Samples were centrifuged at $8000 \mathrm{rpm}$ for $10 \mathrm{~min}$ and filtered through $0.2 \mu \mathrm{m}$ membrane filter. The different concentrations of DMF standard solutions were prepared with HPLC grade water and filtered before injection.
2.5. Mobile Phase. The sodium dihydrogen phosphate buffer $(50 \mathrm{mM})$ was used as mobile phase in HPLC analysis. The buffer was prepared in HPLC grade water containing $0.5 \%$ (v/v) acetonitrile having $\mathrm{pH}$ 6.5. Mobile phase was degassed in a sonication chamber and filtered through $0.45 \mu \mathrm{m}$ membrane vacuum filter (Pall Corporation, USA).

2.6. Chromatographic Conditions. Analysis was carried out by using Waters HPLC (Milford, MA, USA) equipped with Waters 515 binary pumps, Ultraviolet detector Waters 2489 set at $210 \mathrm{~nm}$. The C8 Sunfire column having $250 \times 4.6 \mathrm{~mm}$ particle size $5 \mu \mathrm{m}$ was used at room temperature. Empower 2 programme (Waters) was used for data acquisition and processing on personal computer. Isocratic elution of buffer at a flow rate of $1 \mathrm{~mL} \mathrm{~min}^{-1}$ was programmed. DMF was identified by comparison with retention time and coelution of authentic standard.

2.7. Analysis of Dimethylamine and Ammonia. The metabolic pathway of DMF degradation follows the production of dimethylamine (DMA) and finally leads to the formation of ammonia [11]. DMA was estimated calorimetrically by using Cullis and Waddington [15]. The concentration of ammonia was determined as described by Schär et al. [16].

2.8. HPLC Method and Injection Conditions. The HPLC conditions were optimized for DMF analysis. Before starting the analysis, the column was thoroughly washed with methanol followed by HPLC grade water with different flow rates. Further, the column was completely stabilized by mobile phase ( $\mathrm{pH}$ 6.5) at increasing flow rates from 0.6 to $1 \mathrm{~mL} / \mathrm{min}$ for $2 \mathrm{~h}$. After stabilization, the flow rate of mobile phase was maintained at $1 \mathrm{~mL} / \mathrm{min}$ in room temperature. Stabilization of column is an essential step during the analysis, which helps the complete interaction of analyte with the mobile phase yield better separation. The injections of both standard and sample were filtered through $0.2 \mu \mathrm{m}$ to avoid bacterial contamination with mobile phase. The injection volume was maintained at $10 \mu \mathrm{L}$ for both standard and sample injections for estimation of DMF concentration. The octasilane groups of C8 column form a hydrophobic nature whereas the DMF is completely miscible with the hydrophilic mobile phase yielding a reverse phase interaction during the separation. This interphasic action between the DMF and the column matrix allows easier separation.

2.9. Standard Calibration Curve. Estimation method was calibrated out by constructing standard linear curve at a concentration range from $0.2 \%$ to $1 \%(\mathrm{v} / \mathrm{v})$ DMF. The peak area versu different DMF concentrations was used for the construction of linear curve. The linear range was optimized by injecting 5 different concentrations in triplicate.

\subsection{Method Validation}

2.10.1. Accuracy. The accuracy of the method was performed to understand the closeness of each method to the initial 


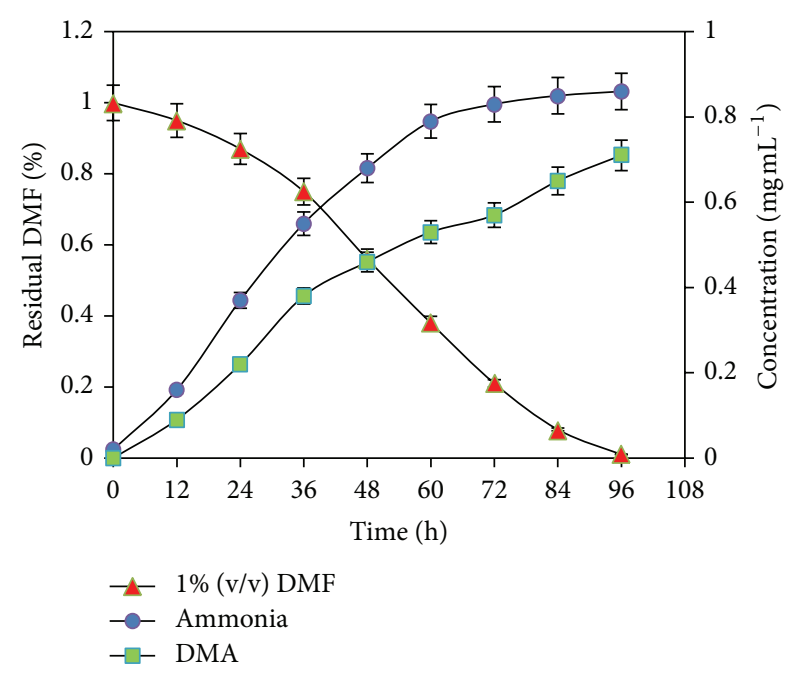

FIgure 1: Degradation of $1 \%(\mathrm{v} / \mathrm{v})$ DMF by $P$. denitrificans SD1 and accumulation of DMA and ammonia in the spent medium at regular intervals of time.

concentration of DMF. Four dilutions of DMF $0.25 \%, 0.5 \%$, $0.75 \%$, and $1 \%(\mathrm{v} / \mathrm{v})$ were separately injected to the column by maintaining the same conditions in all the trials. The percentage recovery of each DMF concentration was compared with the initial DMF concentration in all the set of experiments [17].

2.10.2. Precision. Precision of a method is a measure of degree of agreement among individual tests results obtained when the method is applied to multiple sampling of a homogenous sample. This parameter was executed by taking a single concentration $0.5 \%(\mathrm{v} / \mathrm{v})$ DMF and investigated the reproducibility of the method under normal operating circumstances (which include sampling, sample preparation, and analysis). The analysis was performed 6 times to obtain statistically valid results. The precision is expressed by calculating the percent relative standard deviation (RSD) by using the following equation [17]:

$$
\% \mathrm{RSD}=\frac{\text { Standard deviation } \times 100}{\text { mean }} .
$$

2.10.3. Limit of Detection (LOD) and Limit of Quantification (LOQ). Limit of detection (LOD) and limit of quantification (LOQ) were measured with respect to the signal to noise ratio, where the LOD is the lowest concentration of DMF can be detected but not necessarily quantified that, whereas the LOQ is the lowest concentration of DMF that can be determined with acceptable precision and accuracy. In this set of experiments, the signal to noise ratio was executed by comparing the signals from samples with known concentration of DMF with those of blank samples to establish the minimum concentration at which the DMF can be reliably detected and quantified $[17,18]$.

\section{Results and Discussion}

Removal of DMF was successfully achieved by inoculating the bacterial strain Paracoccus denitrificans SD1. The organism is potent to utilize DMF as sole source of carbon and nitrogen in the mineral salt medium [13]. Monitoring of DMF degradation at a regular interval of time by the strain is a prime criterion in degradation studies. Some previous studies have used gas chromatography for the estimation of DMF $[9,10]$, while some recent investigations followed high performance liquid chromatography for DMF estimation [1113]. The DMF was subsequently degraded into DMA, formic acid, and ammonia as a final product. Where the secondary amine (DMA) can be estimated spectrophotometrically in the presence of sodium nitroprusside, a blue colored complex can be measured at $565 \mathrm{~nm}$ [15] and DMA further converts into ammonia as a final product. Accumulation of ammonia in the spent medium is also an evidence of mineralization of DMF [11]. The formation of DMA and ammonia in the medium is shown in Figure 1.

The $1 \%(\mathrm{v} / \mathrm{v})$ DMF was completely degraded in $96 \mathrm{~h}$ of incubations, whereas the positive control (without bacterial cells) showed the persistency of $99 \%$ of residual DMF in the spent medium because of low vaporization rate. However, these methods minimize the time of estimation and avoid the prederivatization process required to analyze DMA in gas chromatograph. As per the existing literature available so far, apart from chromatographic methods, no other methods are reported for DMF estimation. Generally the gas chromatographic methods are practiced for the analysis of volatile compounds. However for the analysis of residual sample that forms aqueous solutions, the samples need to be extracted and derivatized in order to be analyzed by GC. However the liquid chromatography condition enables the direct analysis of sample from aqueous fermentation medium. This helps to overcome the tedious sample preparations practiced in GC analysis. In view of these aspects, the present investigation points towards the liquid chromatographic estimation and quantification of DMF from the spent medium. The method optimized from preprocessing conditions to analysis of the data interpretation is described in the following sections.

3.1. Standard Calibration Curve. The standard linear curve was constructed as described earlier [19]. The DMF concentrations were taken with increasing concentration range from $0.2 \%$ to $1.0 \%(\mathrm{v} / \mathrm{v})$. The standard curve represents the peak area of specific concentration of DMF obtained from the chromatographic data. The peak area data was electronically generated by the system with response to the injection concentration. The linearity of the curve was optimized with different dilutions of DMF concentration. It was determined by relative standard deviation and found to be below 0.25 which is good within the acceptable criteria for all the DMF concentrations (Table 1). Each concentration was injected 6 


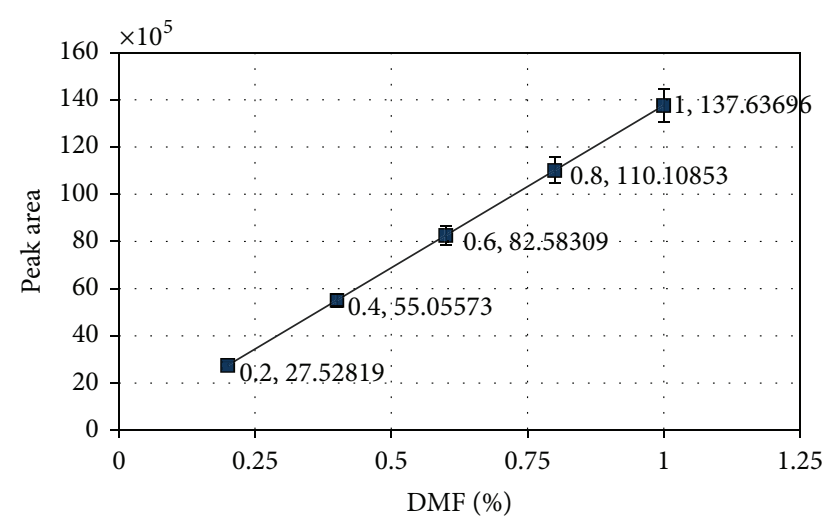

FIGURE 2: Standard calibration curve of DMF at increasing concentrations from $0.2 \%-1 \%(\mathrm{v} / \mathrm{v})$ verses peak area.

times and the mean of peak area was used for construction of standard graph (Figure 2).

3.2. Validation and Estimation of DMF. Residual DMF was estimated by injecting the sample withdrawn from spent medium, where the retention time of DMF was found to be $9.35 \mathrm{~min}$. The standard DMF chromatogram generated by the system is shown in Figure 3(a). The sample injections were carried out as the same conditions maintained in the standard calibration curve of different DMF concentrations. The peak areas of samples were compared with the standard area by taking reference of standard linear curve. The residual concentration of DMF in the sample was estimated by using the following equation:

$$
\begin{aligned}
\operatorname{DMF}(\%)= & \frac{\text { Sample area }}{\text { Standard area }} \times \frac{\text { Standard dilutions }}{\text { Sample dilutions }} \\
& \times \text { Purity of DMF. }
\end{aligned}
$$

The DMF concentration was found to be decreasing with higher incubation periods. This is due to continuous utilization of DMF by bacterial strain for growth in the fermentation medium. The chromatograms generated at $0 \mathrm{~h}$, $60 \mathrm{~h}$, and $96 \mathrm{~h}$ were overlaid in Figure 3(b). This could be a better way of expressing the decrease of DMF concentration at different intervals of time.

Precision of the method was examined by maintaining the same sampling conditions, preparation of sample, and injection volume for a single concentration of DMF. The method was carried out at $0.5 \%(\mathrm{v} / \mathrm{v})$ DMF 6 times to understand the deviation in all the tested trials, where peak area, retention time, and percentage recoveries of DMF were documented, and relative standard deviation (RSD) was calculated in all the trials (Table 2). The result reveals that standard deviation of peak area, retention time, and percentage recoveries were $0.10,0.01$, and 0.2 , respectively, and all are well acceptable range of precision parameters. This advocates the good reproducibility in all the tested conditions.
TABLE 1: Relative standard deviation of each concentration of DMF calibration curve.

\begin{tabular}{lcc}
\hline $\begin{array}{l}\text { Concentration } \\
\text { of DMF (\%) }\end{array}$ & $\begin{array}{c}\text { Average peak area of } 4 \text { independent } \\
\text { times }\end{array}$ & \% RSD \\
\hline 0.2 & 2752819 & 0.24 \\
0.4 & 5505573 & 0.21 \\
0.6 & 8258309 & 0.19 \\
0.8 & 11810853 & 0.20 \\
1.0 & 13763696 & 0.16 \\
\hline
\end{tabular}

TABle 2: Precision results at $0.5 \%(\mathrm{v} / \mathrm{v})$ DMF analysis.

\begin{tabular}{lccc}
\hline No. of analysis & Peak area & Retention time & \% Recovery \\
\hline 1 & 8134734 & 9.35 & 99.12 \\
2 & 8134729 & 9.31 & 99.09 \\
3 & 8134712 & 9.35 & 99.23 \\
4 & 8134709 & 9.32 & 99.56 \\
5 & 8134730 & 9.34 & 98.97 \\
6 & 8134718 & 9.34 & 99.06 \\
Mean & 8134722 & 9.33 & 99.17 \\
\% RSD & 0.10 & 0.01 & 0.20 \\
\hline
\end{tabular}

The accuracy of the method was carried out in four different concentrations in a range of $0.25 \%, 0.5 \%, 0.75 \%$, and $1.0 \%(\mathrm{v} / \mathrm{v})$ DMF. To investigate the accuracy of the method in every concentration, the sample was prepared in three dilutions like initial, half of initial, and quaternary of initial concentrations. Throughout the analysis peak area and percentage recovery of each dilution were studied. The result reveals that the method was accurate in all the tested concentrations where the percentage RSD was found to be $0.26,0.15,0.19$, and 0.17 of $0.25 \%, 0.5 \%, 0.75 \%$, and $1.0 \%(\mathrm{v} / \mathrm{v})$ DMF, respectively (Table 3 ). All diluted samples of DMF at each concentration are within the acceptable limit that confirms the method is accurate for DMF estimation.

The LOD was found to be $0.12 \mathrm{mg} \mathrm{L}^{-1}$ when $S / N$ ratio was $2: 1$. Similarly LOQ is the lowest concentration of DMF and can be quantified by taking precision and accuracy into consideration, whereas the LOQ was found to be $0.40 \mathrm{mg} \mathrm{L}^{-1}$ when $S / N$ ratio was $10: 1$ during the analysis.

\section{Conclusion}

The method advocates the estimation of DMF from the spent medium after bacterial degradation. The high performance liquid chromatography enables the precise analysis of residual DMF in the liquid phase. The validation of this method establishes the significant improvements for the detection and quantification of DMF. This implies the accurate interpretation of DMF analysis after biodegradation in the aqueous medium. 


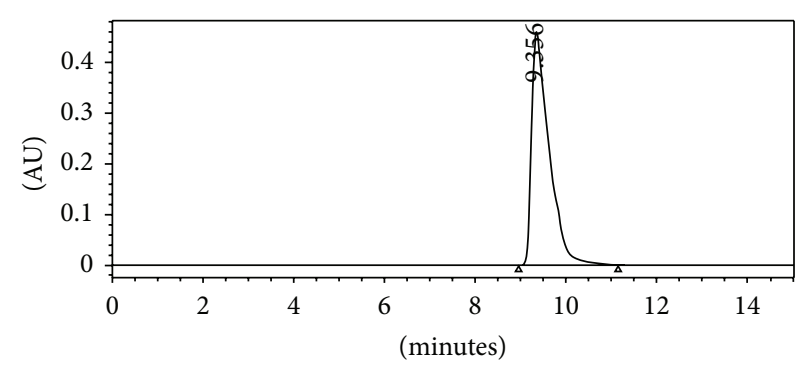

(a)

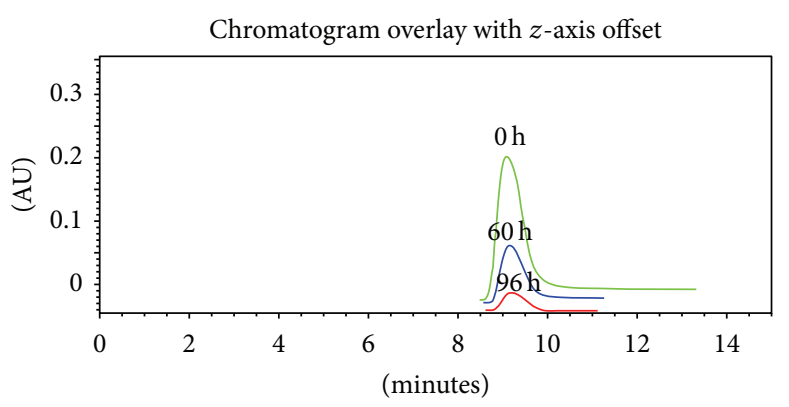

(b)

FIGURE 3: (a) HPLC elution profile of authentic DMF at a retention time of 9.35. (b) Overlaid chromatograms of residual DMF at different intervals from the spent medium.

TABLE 3: Accuracy results of DMF estimation method at different dilutions.

\begin{tabular}{|c|c|c|c|c|}
\hline DMF (\%) & Injections & Peak area & $\%$ Recovery & $\% \mathrm{RSD}$ \\
\hline \multirow{3}{*}{0.25} & Initial & 3962929 & 99.12 & \multirow{3}{*}{0.26} \\
\hline & Half dilution & 1982512 & 99.49 & \\
\hline & Quaternary dilution & 991319 & 98.97 & \\
\hline \multirow{3}{*}{0.50} & Initial & 8134734 & 98.97 & \multirow{3}{*}{0.15} \\
\hline & Half dilution of initial & 3995677 & 99.15 & \\
\hline & Quaternary dilution & 2012345 & 99.27 & \\
\hline \multirow{3}{*}{0.75} & Initial & 11219687 & 99.14 & \multirow{3}{*}{0.19} \\
\hline & Half dilution of initial & 5598767 & 99.43 & \\
\hline & Quaternary dilution & 2804845 & 99.06 & \\
\hline \multirow{3}{*}{1.0} & Initial & 13764192 & 99.24 & \multirow{3}{*}{0.17} \\
\hline & Half dilution of initial & 68902871 & 98.98 & \\
\hline & Quaternary dilution & 3441065 & 99.32 & \\
\hline
\end{tabular}

\section{Acknowledgments}

Sanjeevkumar Sanganal acknowledges CSIR, New Delhi, for financial assistance through Senior Research Fellowship. The authors also wish to thank the University Grants Commission (UGC), New Delhi, for supporting the department through the UGC-SAP programme.

\section{References}

[1] Y. Hasegawa, M. Matsuo, Y. Sigemoto, T. Sakai, and T. Tokuyama, "Purification and characterization of N,N-Dimethylformamidase from Alcaligenes sp. KUFA-1," Journal of Fermentation and Bioengineering, vol. 84, no. 6, pp. 543-547, 1997.

[2] M. J. Twiner, M. Hirst, A. Valenciano, T. R. Zacharewski, and S. J. Dixon, "N,N-dimethylformamide modulates acid extrusion from murine hepatoma cells," Toxicology and Applied Pharmacology, vol. 153, no. 2, pp. 143-151, 1998.

[3] K. C. A. Bromley-Challenor, N. Caggiano, and J. S. Knapp, "Bacterial growth on $N, N$-dimethylformamide: implications for the biotreatment of industrial wastewater," Journal of Industrial Microbiology and Biotechnology, vol. 25, no. 1, pp. 8-16, 2000.

[4] T. H. Kim, Y. W. Kim, S. M. Shin, C. W. Kim, I. J. Yu, and S. G. Kim, "Synergistic hepatotoxicity of $N, N$-dimethylformamide with carbon tetrachloride in association with endoplasmic reticulum stress," Chemico-Biological Interactions, vol. 184, no. 3, pp. 492-501, 2010.

[5] J. Mraz, "N-Acetyl-S-(N-methylcarbamoyl) cysteine (AMCC), the mercapturic acid of $N, N$-dimethylformamide (DMF): metabolic formation, methods of analysis, application in biological monitoring," in Mercapturic Acids as Biomarkers of Exposure to Industrial Chemicals, L. Ambrosi, L. Soleo, S. Ghittori, L. Maestri, and M. Imbriani, Eds., pp. 111-118, Maugeri Foundation Books, PI-ME Press, Pavia, Italy, 2001.

[6] F. Brugnone, L. Perbellini, and E. Gaffuri, "N,N-dimethylformamide concentration in environmental and alveolar air in an artificial leather factory," British Journal of Industrial Medicine, vol. 37, no. 2, pp. 185-188, 1980.

[7] J. Mraz and H. Nohova, "Percutaneous absorption of $N, N$ dimethylformamide in humans," International Archives of Occupational and Environmental Health, vol. 64, no. 2, pp. 79-83, 1992.

[8] L. Dziewit, M. Dmowski, J. Baj, and D. Bartosik, "Plasmid pAMI2 of Paracoccus aminophilus JCM 7686 carries $N, N$ dimethylformamide degradation-related genes whose expression is activated by a LuxR family regulator," Applied and Environmental Microbiology, vol. 76, no. 6, pp. 1861-1869, 2010.

[9] O. Ghisalba, P. Cevey, M. Kuenzi, and H. P. Schar, "Biodegradation of chemical waste by specialized methylotrophs, an alternative to physical methods of waste disposal," Conservation and Recycling, vol. 8, no. 1-2, pp. 47-71, 1985. 
[10] T. Urakami, H. Araki, H. Oyanagi, K. I. Suzuki, and K. Komagata, "Paracoccus aminophilus sp. nov. and Paracoccus aminovorans sp. nov., which utilize $N$, N-dimethylformamide," International Journal of Systematic Bacteriology, vol. 40, no. 3, pp. 287-291, 1990.

[11] Y. Veeranagouda, P. V. Emmanuel Paul, P. Gorla, D. Siddavattam, and T. B. Karegoudar, "Complete mineralisation of dimethylformamide by Ochrobactrum sp. DGVK1 isolated from the soil samples collected from the coalmine leftovers," Applied Microbiology and Biotechnology, vol. 71, no. 3, pp. 369-375, 2006.

[12] S. Swaroop, P. Sughosh, and G. Ramanathan, "Biomineralization of $N, N$-dimethylformamide by Paracoccus sp. strain DMF," Journal of Hazardous Materials, vol. 171, no. 1-3, pp. 268272, 2009.

[13] S. S. Kumar, M. S. Kumar, D. Siddavatam, and T. B. Karegoudar, "Generation of continuous packed bed reactor with PVAalginate blend immobilized Ochrobactrum sp. DGVK1 cells for effective removal of $\mathrm{N}, \mathrm{N}$-dimethylformamide from industrial effluents," Journal of Hazardous Materials, vol. 199-200, pp. 5863, 2012.

[14] D. Siddavattam, T. B. Karegoudar, S. K. Mudde et al., "Genome of a novel isolate of Paracoccus denitrificans capable of degrading N, N-Dimethylformamide," Journal of Bacteriology, vol. 193, pp. 5598-5599, 2011.

[15] C. F. Cullis and D. J. Waddington, "The colorimetric determination of secondary amines," Analytica Chimica Acta, vol. 15, pp. 158-163, 1956.

[16] H. P. Schär, W. Holzmann, G. M. Ramos, and O. Ghisalba, "Purification and characterization of $N, N$-dimethylformamidease from Pseudomonas DMF3/3," Europien Journal of Biochemistry, vol. 158, pp. 469-475, 1986.

[17] United States Pharmacopeia XXI I, United States Pharmacopeial Convention, Rockvilie, Md, USA, 1990.

[18] Validation of Compedial Assays-Guidelines, Pharmacopeial Convention, Rockvilie, Md, USA, 1985.

[19] E. Armaforte, S. Carri, G. Ferri, and M. F. Caboni, "Highperformance liquid chromatography determination of phenyllactic acid in MRS broth," Journal of Chromatography A, vol. 1131, no. 1-2, pp. 281-284, 2006. 

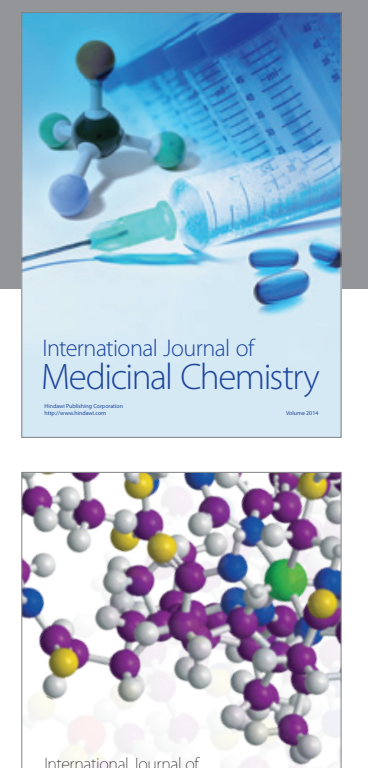

\section{Carbohydrate} Chemistry

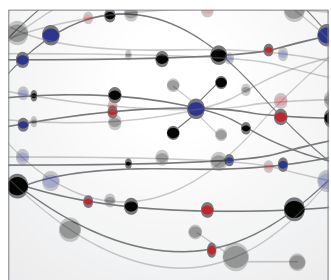

The Scientific World Journal
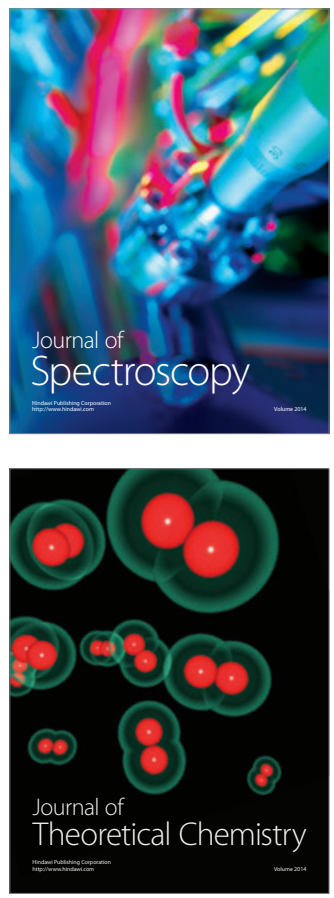
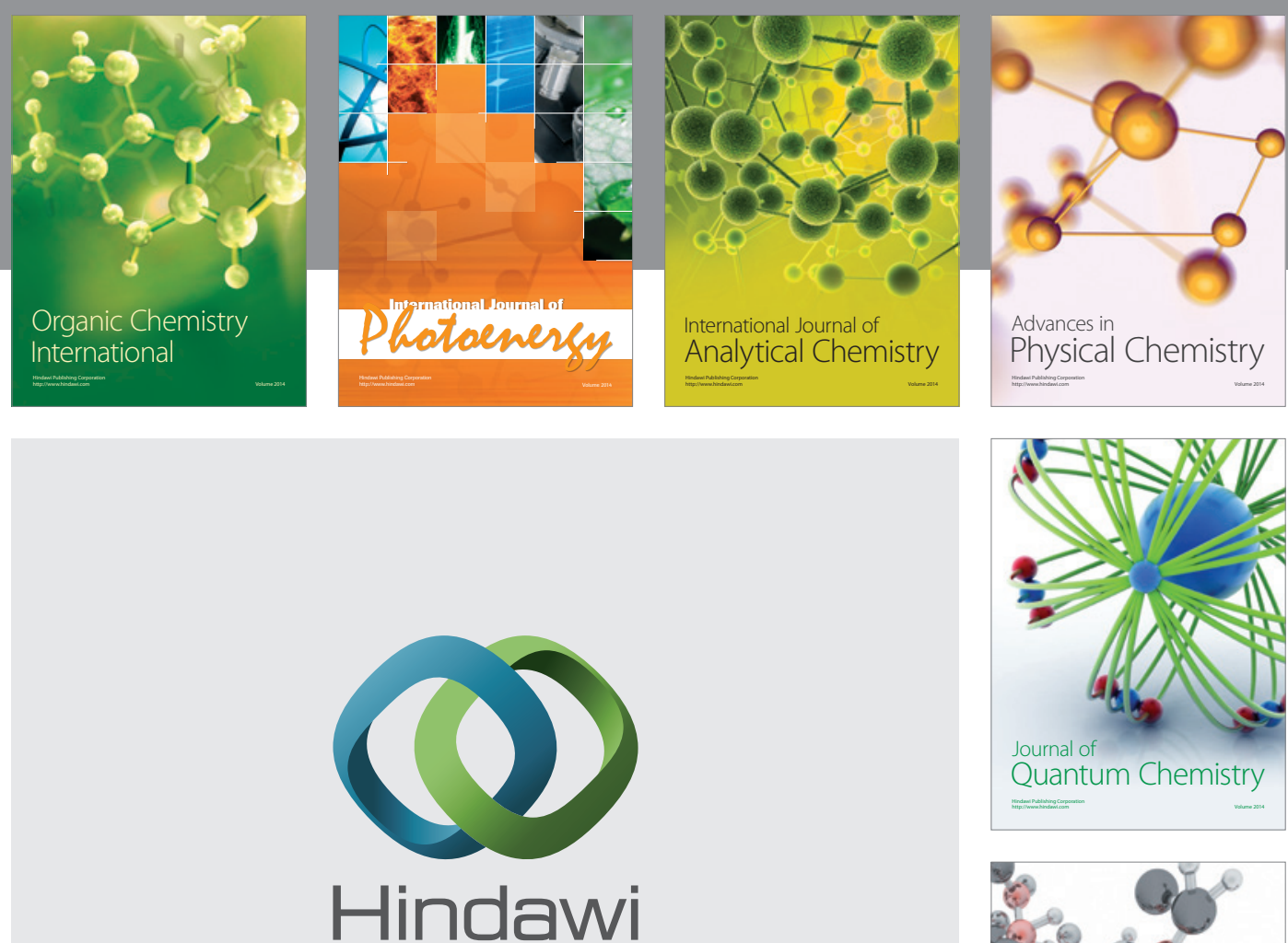

Submit your manuscripts at

http://www.hindawi.com

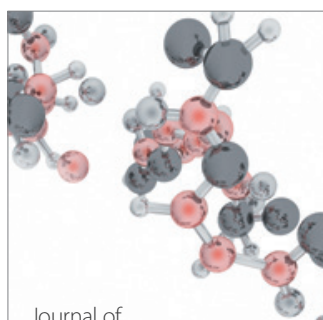

Analytical Methods

in Chemistry

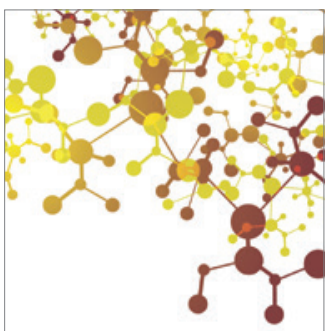

Journal of

Applied Chemistry

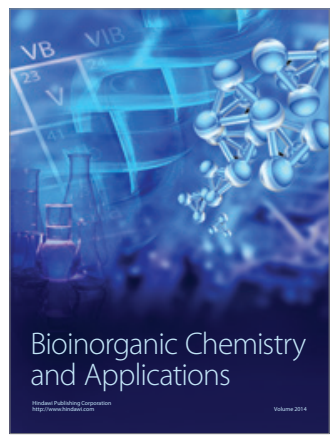

Inorganic Chemistry
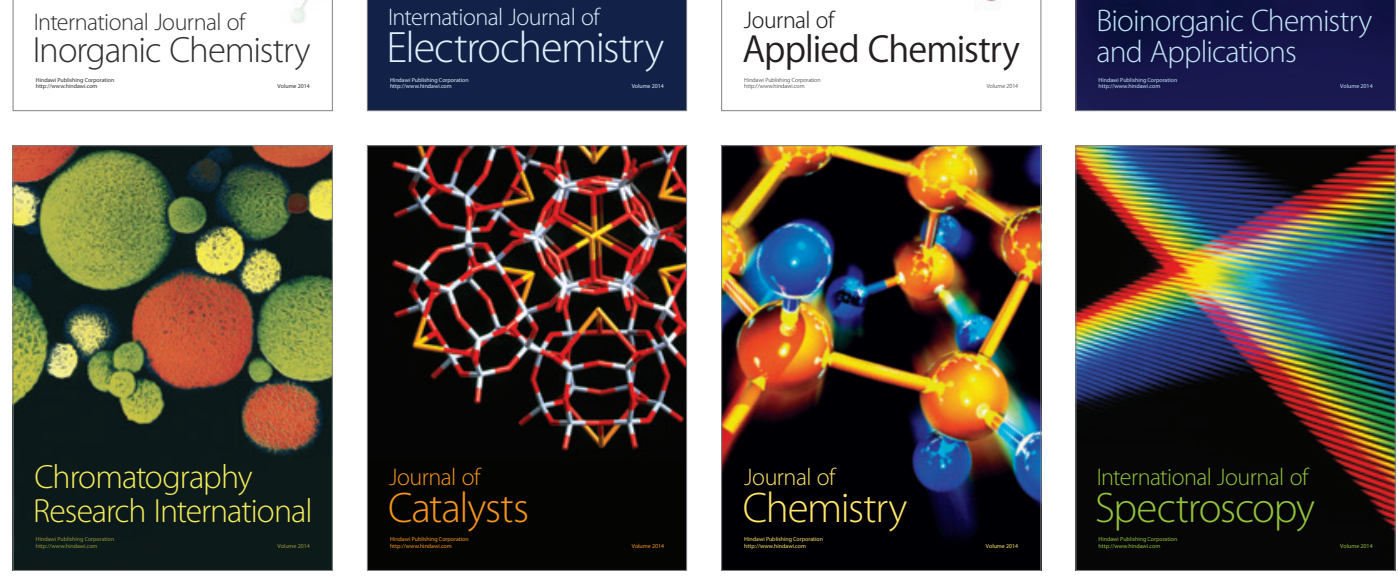